\title{
Newborn 2D materials for flexible energy conversion and storage
}

\author{
Jinxin Liu, Hui Cao, Bei Jiang, Yinghui Xue and Lei Fu*
}

\begin{abstract}
Newborn two-dimensional materials (NB2DMs) beyond graphene such as transition metal dichalcogenides (TMDs) exhibit excellent optoelectronic and mechanical properties as well as high theoretical specific capacity, which make them become the promising building blocks of flexible energy devices related to energy conversion and storage. Compared to graphene with zero band gap or traditional friable materials such as $\mathrm{Si}$, these NB2DMs are more suitable to construct flexible devices as active layers of optoelectronic devices or as active materials for batteries. The present review focuses on the recent advances in bendable energy devices based on NB2DMs, including batteries, supercapacitors (SCs), solar cells, photodetectors and nanogenerators (NGs). The NB2DMs pave a new way to construct next-generation flexible energy devices with improved performance and we believe that those devices will be seen in our daily life and change our lifestyle in the immediate future.
\end{abstract}

Keywords: 2D materials, transition metal dichalcogenides, flexible energy conversion and storage

\section{INTRODUCTION}

Nowadays, wearable equipment plays an important role in our daily life [1-3]. The development of these electronic equipments, such as wearable devices, rollup displays and bendable mobile phones has caught the great interest of the flexible applications. Among them, flexible energy device related to energy conversion and storage is one of the most significant fields on account of the global energy crisis and the requirement of portability. Batteries, supercapacitors (SCs), photodetectors, solar cells and nanogenerators (NGs) have attracted enough attention of researchers. These devices could exhibit stable performance after repeated stretching [4-6]. Certainly, each component of the flexible devices, such as active layers of the optoelectronic devices and current collectors of the batteries, should be mechanically stable and flexible [7-8]. Furthermore, the active materials should also possess good electrical conductivities, high theoretical specific capacity for energy storage applications [5] or sizable band gaps, high quantum yield for optoelectronic devices related to energy conversion [9]. Two-dimensional (2D) materials usually exhibit excellent mechanical properties owing to their atomic thickness, which makes them become the ideal candidates of the flexible devices. As the first 2D material with good electrical properties, graphene has attracted significant attention as the conductive electrodes of the devices [5]. However, it is unsuitable for graphene to serve as the promising active materials in the energy applications due to its gapless property [10] and low theoretical specific capacity [11]. Nevertheless, newborn two-dimensional materials (NB2DMs) beyond graphene such as transition metal dichalcogenides (TMDs) and black phosphorus (BP) could satisfy these devices owing to their unique and attractive plastic, electrochemical and photoelectrical properties [12-14].

These planar materials generally exhibit tunable band gaps related to thickness, which makes them promising candidates for flexible optoelectronic applications [15]. Meanwhile, larger interlayer spacing, high theoretical specific capacity and power density make them very suitable in stretchable energy storage devices [16,17]. Induced by their excellent mechanical properties $[18,19]$, the NB2DMs have been investigated in several flexible applications, such as batteries [20], SCs [21], photodetectors [22], etc.

Here, we reviewed the recent progress of the NB2DMsbased flexible devices related to energy conversion and storage. In the first part, we summarized the latest successful examples of flexible batteries and SCs based on these materials with high theoretical specific capacity and power den-

Laboratory of Advanced Nanomaterials, College of Chemistry and Molecular Science, Wuhan University, Wuhan 430072, China

${ }^{*}$ Corresponding author (email: leifu@whu.edu.cn) 
sity. In the following section, we presented the improvement of the NB2DMs-based flexible devices related to the energy conversion. Finally, we briefly outlined the recent achievements in the flexible energy applications based on these materials.

\section{FLEXIBLE DEVICES FOR ENERGY STORAGE}

To meet the demand for rapid development of portable, and wearable electronic devices, extensive efforts have been devoted to developing flexible energy storage application [23]. Those devices, such as flexible lithium ion batteries (LIBs) and SCs, can be utilized to store energy without dramatic decrease of their performance when subjected to repeated bending, folding and stretching. Graphene materials with excellent mechanical flexibility and conductivity possibly can provide the devices with good performance $[25,27]$. However, when mixed with active electrode materials, graphene will diminish energy density and power density of flexible devices. Thus, tremendous research has been devoted to developing flexible energy devices based on the NB2DMs. Similar to graphene, $\mathrm{MX}_{2}(\mathrm{M}=\mathrm{Ti}, \mathrm{Nb}$, $\mathrm{Mo}, \mathrm{W}, \mathrm{Ta} ; \mathrm{X}=\mathrm{S}, \mathrm{Se}, \mathrm{Te}$ ) and $\mathrm{BP}$ with strong in-plane bonds and weak out-of-plane bonds have received considerable attention for lithium redox reversibility and higher theoretical specific capacity $[16,28,29]$. The larger interlayer spacing between the NB2DMs layers allows reversible and rapid ions intercalation and deintercalation without any significant change in volume [17]. Furthermore, the NB2DMs with excellent flexibility can provide the devices with exceptional performance under bending or stretching conditions. This section was organized in two main parts, flexible batteries and SCs. The advancements and the challenges of the NB2DMs devices for energy storage were discussed and summarized.

\section{Batteries}

A battery is an energy storage device that can transform chemical energy into electricity. In order to satisfy the rapidly increasing demands of ever new portable devices, it is urgently required to develop advanced flexible batteries with outstanding electrochemical performance [30], such as flexible LIBs, flexible sodium ion batteries (SIBs), flexible lithium- $\mathrm{O}_{2}$ batteries, flexible lithium sulfur batteries (LSBs) and so on. An ideal flexible battery is commonly composed of flexible electrode materials with higher theoretical capacity, while separators, electrolytes and packing materials are usually bendable polymer films [4].

\section{Lithium ion batteries}

LIB is one of the rechargeable battery types in which lithium compound is selected as the electrode material. The working principle of the internal LIBs is based on the chemical reaction of lithiation and delithiation process for the electrode active materials [7]. Due to the high energy and power density, high operating voltage, low self-discharge rate and relatively long-term cycling stability, LIBs become one of the most attractive power sources of plenty of energy storage devices [16,31]. Conventional LIBs are hard to satisfy particular requirements of flexible electronics in tough environmental situations, for electrode active materials are usually mixed with conductive additives and polymer binders [16], thus materials are easily separated from each other and affect the performance of the flexible LIBs. Flexible LIBs not only need to show excellent electrochemical performance and safe operation but also to exhibit superior flexibility. The softness, bendability and high capacity of the nanostructured NB2DMs render them as the potential candidates of the flexible LIBs. In order to make flexible batteries get better practical applications in the daily life, many efforts have been devoted to realizing mechanical flexibility of the NB2DMs-based batteries.

Electrochemical active materials, electrolytes and collectors are three main parts, which are widely studied in flexible LIBs [32]. Among the various functional electrode materials explored for flexible LIBs, the NB2DMs have gathered increasing attentions. $\mathrm{MoS}_{2}$, a kind of TMDs with the similar layered structure as graphite, allows reversible $\mathrm{Li}^{+}$ intercalation/extraction and it possesses an ultrahigh theoretical specific capacity of $670 \mathrm{~mA} \mathrm{~h} \mathrm{~g}$ (based on $4 \mathrm{~mol}$ of $\mathrm{Li}^{+}$insertion). It is usually much higher than that of graphene (usually in the range of 200 to $500 \mathrm{~mA} \mathrm{~h} \mathrm{~g}^{-1}$ ) [24,29], which makes $\mathrm{MoS}_{2}$ the most popular next-generation materials in LIBs [20]. Chen et al. [24] introduced $\mathrm{Fe}_{3} \mathrm{O}_{4}$ nanoparticles into $\mathrm{MoS}_{2}$ nanosheets to achieve superior electrochemical performance (Figs la and b). A flexible $\mathrm{MoS}_{2} / \mathrm{Fe}_{3} \mathrm{O}_{4}$ composite anode was synthesized by a facile hydrothermal method, the morphology of the obtained $\mathrm{MoS}_{2}$ nanosheets was similar to that of graphene [33]. In this work, $\mathrm{MoS}_{2}$ nanosheets functioned as flexible substrates, and $\mathrm{Fe}_{3} \mathrm{O}_{4}$ nanoparticles were good spacers in this composite anode. The composite was capable of accommodating the volume changes during cycling, thus facilitating electrolyte penetration and faster lithium ion transport throughout the electrode. And during the subsequent electrochemical tests, the battery shows superior cyclic and rate performance, and enhanced reversible capacity of $1033 \mathrm{~mA} \mathrm{~h} \mathrm{~g}^{-1}\left(2000 \mathrm{~mA} \mathrm{~g}^{-1}\right)$ and $224 \mathrm{~mA} \mathrm{~h} \mathrm{~g}^{-1}$ 


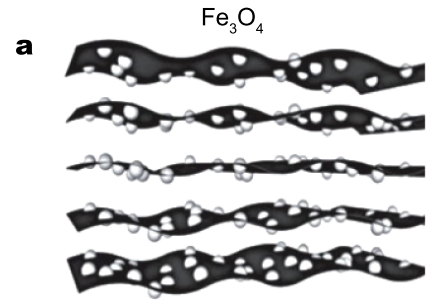

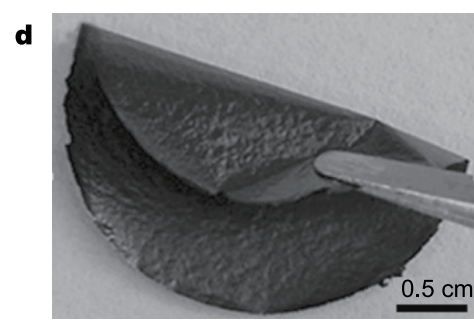

still accessible for

electrolyte penetration

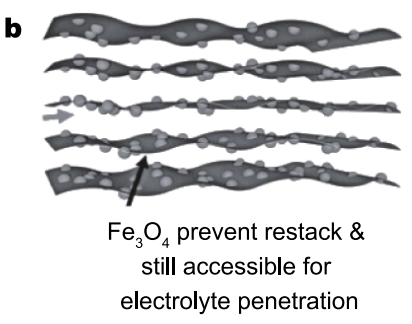

c

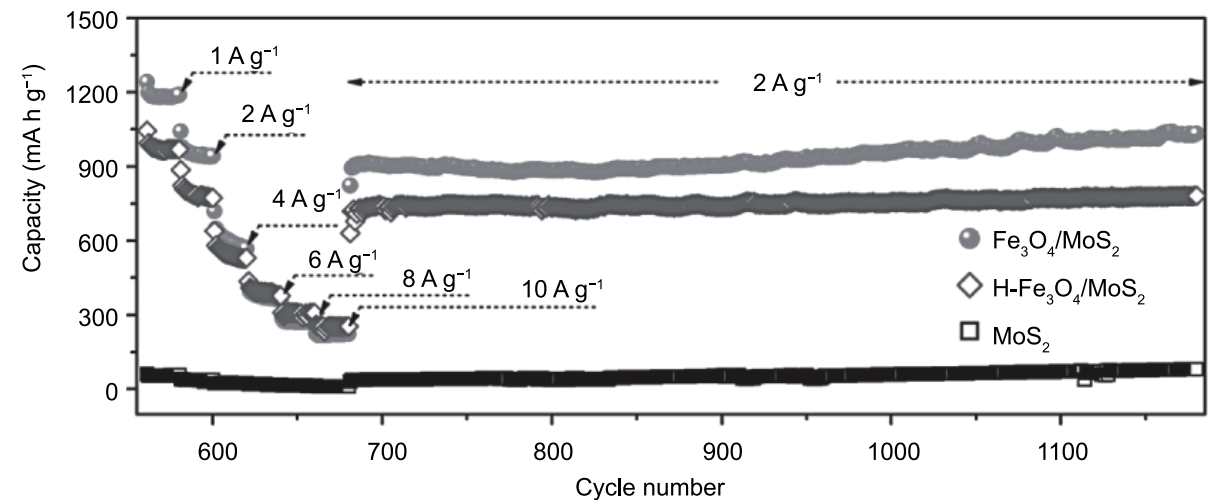

Cycle number
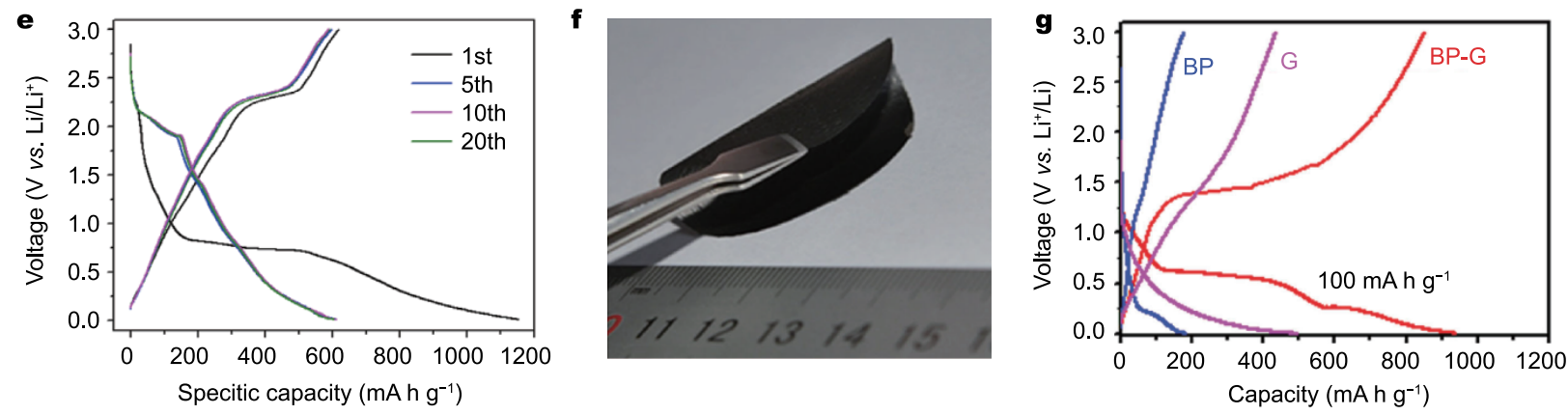

Figure 1 (a) The morphologies of $\mathrm{Fe}_{3} \mathrm{O}_{4} / \mathrm{MoS}_{2}$ electrodes before cycling. (b) The morphologies of composite electrode after cycling. (c) Cyclic performances of $\mathrm{Fe}_{3} \mathrm{O}_{4} / \mathrm{MoS}_{2}, \mathrm{H}-\mathrm{Fe}_{3} \mathrm{O}_{4} / \mathrm{MoS}_{2}$, and $\mathrm{MoS}_{2}$ from cycle number 561 to 1180. Reproduced with permission from Ref. [24]. Copyright 2014, Wiley-VCH Verlag GmbH \& Co. KGaA. (d) A digital photograph of WS 2 /rGO WG-2-1 paper shows good flexibility. (e) Charge-discharge curves of the WG-2-1 paper. Reproduced with permission from Ref. [25]. Copyright 2014, Elsevier. (f) Photograph of a BP-G hybrid paper, showing its good flexibility. (g) The second galvanostatic charge/discharge profiles of the BP nanosheets, G paper, and BP-G hybrid paper electrodes at a current density of $100 \mathrm{~mA} \mathrm{~g}^{-1}$ within a potential window of $0.001-3 \mathrm{~V}\left(v s . \mathrm{Li}^{+} / \mathrm{Li}^{0}\right)$. Reproduced with permission from Ref. [26]. Copyright 2016, Wiley-VCH Verlag $\mathrm{GmbH} \&$ Co. KGaA.

$\left(10,000 \mathrm{~mA} \mathrm{~g}^{-1}\right)$, respectively (Fig. 1c). 2D MoS holds great potential in flexible energy storage for higher capacity and as flexible substrate.

Reduced graphene oxide (rGO) with excellent flexibility and good electrical conductivity, attracted increasing and considerable attention for fabricating flexible electrodes [34,35], however, its low capacity limited its final application [36]. $\mathrm{WS}_{2}$ is an attractive $2 \mathrm{D}$ layered anode material and its theoretical specific capacity $(433 \mathrm{~mA} \mathrm{~h}$ $\mathrm{g}^{-1}$ ) is higher than that of graphene, but it also suffers from severe restacking and low electronic conductivity during electrochemical reaction [25]. To solve this, Liu et al. [25] developed a simple filtrated assembling method and hydrothermal reduction process to prepare flexible lamellar $\mathrm{WS}_{2} / \mathrm{rGO}$ paper. When it functioned as binder-free anodes for LIBs, the composite paper demonstrated good flexibility (Fig. 1d). In uniform hybrid structures, rGO nanosheets with high conductivity greatly facilitate the transfer of electrons and ions, and efficiently prevent the restacking of electrochemical active materials during the electrochemical $\mathrm{Li}^{+}$insertion/extraction reaction. The hybrid electrode delivers a high initial discharge capacity of about $1154.1 \mathrm{~mA} \mathrm{~h} \mathrm{~g}^{-1}$ (Fig. 1e) and a charge capacity of $619.3 \mathrm{~mA} \mathrm{~h} \mathrm{~g}^{-1}$ (at a current density of $100 \mathrm{~mA} \mathrm{~g}^{-1}$ ). And it also presented excellent cyclic stability and superior rate capacity. After 100 cycles, free-standing composite elec- 
trode still delivered a capacity of $697.7 \mathrm{~mA} \mathrm{~h} \mathrm{~g}^{-1}$. 2D WS 2 sheets with uniform layer structure indicate the potency as binder-free anode materials for flexible LIBs in the future technological innovation.

In addition to these rapid developments of 2D materials for flexible LIBs, atomically thin BP, has recently been considered as a reliable anode material in LIBs. BP possesses a high theoretical specific capacity of $2596 \mathrm{~mA} \mathrm{~h} \mathrm{~g}^{-1}$, which is approximately 7 times that of the widely used graphite (372 $\mathrm{mA} \mathrm{h} \mathrm{g}^{-1}$ ) [11]. Recently, Chen et al. [26] reported their scalable and clean production method for BP. Few-layer BP nanosheets were exfoliated in water via fully utilizing the hydrophilic nature of BP crystals. Then the obtained materials were combined with highly conductive graphene sheets via a vacuum filtration. Owing to great mechanical robustness, the BP/G hybrid paper exhibited superior flexibility, which can be bent to nearly $180^{\circ}$ without any breaking (Fig. 1f), which demonstrates the great potential in the future flexible energy storage. When BP/G hybrid paper was employed as anode in LIBs, it exhibits the electrochemical lithium storage capacity as high as $920 \mathrm{~mA} \mathrm{~h} \mathrm{~g}^{-1}$ at 100 $\mathrm{mA} \mathrm{g}^{-1}$, while for individual BP nanosheets and $\mathrm{G}$ paper electrodes, the capacities drop to $180 \mathrm{~mA} \mathrm{~h} \mathrm{~g}^{-1}$ and $435 \mathrm{~mA}$ $\mathrm{h} \mathrm{g}^{-1}$, respectively (Fig. 1g). In addition, hybrid papers also demonstrate a perfect synergistic effect and great improvement of rate capability and cycling performance. BP fully indicates the potential use as flexible LIBs electrodes and further demonstrates the advantages of the NB2DMs for flexible electrochemical energy storage applications and it will open up more applications for flexible LIBs.

\section{Sodium ion batteries}

As a main power source for portable electronic devices, LIBs lie at the forefront of the present energy storage technologies [37]. In contrast to LIBs, SIBs have attracted increasing attention due to their wider availability, lower cost and similar insertion chemistry property, which makes SIBs a promising candidate for the large-scale energy storage [38]. Sodium is the second advantageous element for battery applications besides lithium and it exhibits a rather negative redox potential of $2.71 \mathrm{~V} v s$. SHE and a very small electrochemical equivalent $\left(0.86 \mathrm{~g} \mathrm{~A} \mathrm{~h}^{-1}\right)$. Thus, in the past few years some researches have been turned to the development of SIBs [38]. However, it is well known that $\mathrm{Na}^{+}$radius is ca. $55 \%$ larger than that of $\mathrm{Li}^{+}$ions [41], which induces larger volume change during the $\mathrm{Na}^{+}$ intercalation/deintercalation process. And it is hard for $\mathrm{Na}^{+}$to form staged intercalation compounds with graphite [42]. Among the various electrode materials explored for flexible SIBs, TMDs with a much larger interlayer spacing have aroused widespread attention for the same layered structure as graphite. An interlayer spacing of bilayered $\mathrm{MoS}_{2}$ is $6.15 \AA$ ( $3.35 \AA$ for graphite). The extremely weak van der Waals interaction and the larger interlayer distance of $\mathrm{MoS}_{2}$ [17] are crucial for sodium ions to efficiently intercalate and deintercalate without significant volume expansion. David et al. [37] developed a free-standing flexible electrode which consisted of acid-exfoliated $\mathrm{MoS}_{2}$ nanoflakes and rGO matrix. The flexible composite papers were fabricated by a simple vacuum filtration of homogeneous dispersions, and thermal reduction. In addition, flexible composite layered papers were also subjected to mechanical tests involving static uniaxial tensile to evaluate the tensile strength and strain to failure parameters (Figs $2 \mathrm{a}$ and b). $40 \mathrm{MoS}_{2}\left(40 \mathrm{MoS}_{2}\right.$ and $60 \mathrm{MoS}_{2}$ for pristine $\mathrm{rGO}$ paper and rGO with $40 \%$ and $60 \%$ of $\mathrm{MoS}_{2}$ in the total weight of the paper, respectively.) exhibited higher fracture strength of approximately 7.8 $\mathrm{MPa}$ and modulus of about $424 \mathrm{MPa}$ than those of $60 \mathrm{MoS}_{2}$, which demonstrates the flexibility of $60 \mathrm{MoS}_{2}$ is better than that of $40 \mathrm{MoS}_{2}$. And $60 \mathrm{MoS}_{2}$ showes a high average strain to failure reaching approximately $2 \%$ and mechanical strength is only $2-3$ $\mathrm{MPa}$, showing an obvious improvement of mechanical stability. When flexible $\mathrm{MoS}_{2} / \mathrm{G}$ composite papers were evaluated as counter electrodes in SIB at room temperature, good cycling performance, stable charge capacity $\left(230 \mathrm{~mA} \mathrm{~h} \mathrm{~g}^{-1}\right)$ and high coulombic efficiency (reaching about 99\%) are achieved (Fig. 2c). The first experimental evidence was offered by this research about reversible electrochemical storage of $\mathrm{Na}$ in layered self-standing $\mathrm{MoS}_{2}$ composite electrodes. It opens new avenues for the applications of large scale free-standing binder-free flexible sodium electrodes for flexible energy storage devices. Limited by the low chemical reactivity of Mo and Se, the application of $\mathrm{MoSe}_{2}$ for SIBs has been rarely investigated so far. Recently flexible $\mathrm{MoSe}_{2}$ /carbon cloth composites were also fabricated by solvothermal method [43]. And it exhibited superior electrochemical performance for SIBs.

In addition, Xiong et al. [39] developed a simple and scalable electrospinning method to synthesize flexible membranes comprised of $\mathrm{MoS}_{2} /$ carbon nanofibers (CNFs). In this composite, the few-layered $\mathrm{MoS}_{2}$ was embedded in CNFs. $\mathrm{Na}^{+}$and electron diffusion distances were greatly shortened, which enhanced the electrical conductivity of $\mathrm{MoS}_{2}$ electrodes. The composite films demonstrated superior membrane flexibility and can be cut into disks when used as flexible free-standing and binder-free electrodes (Fig. 2d). When $\mathrm{MoS}_{2}$-CNFs films were used as the work- 

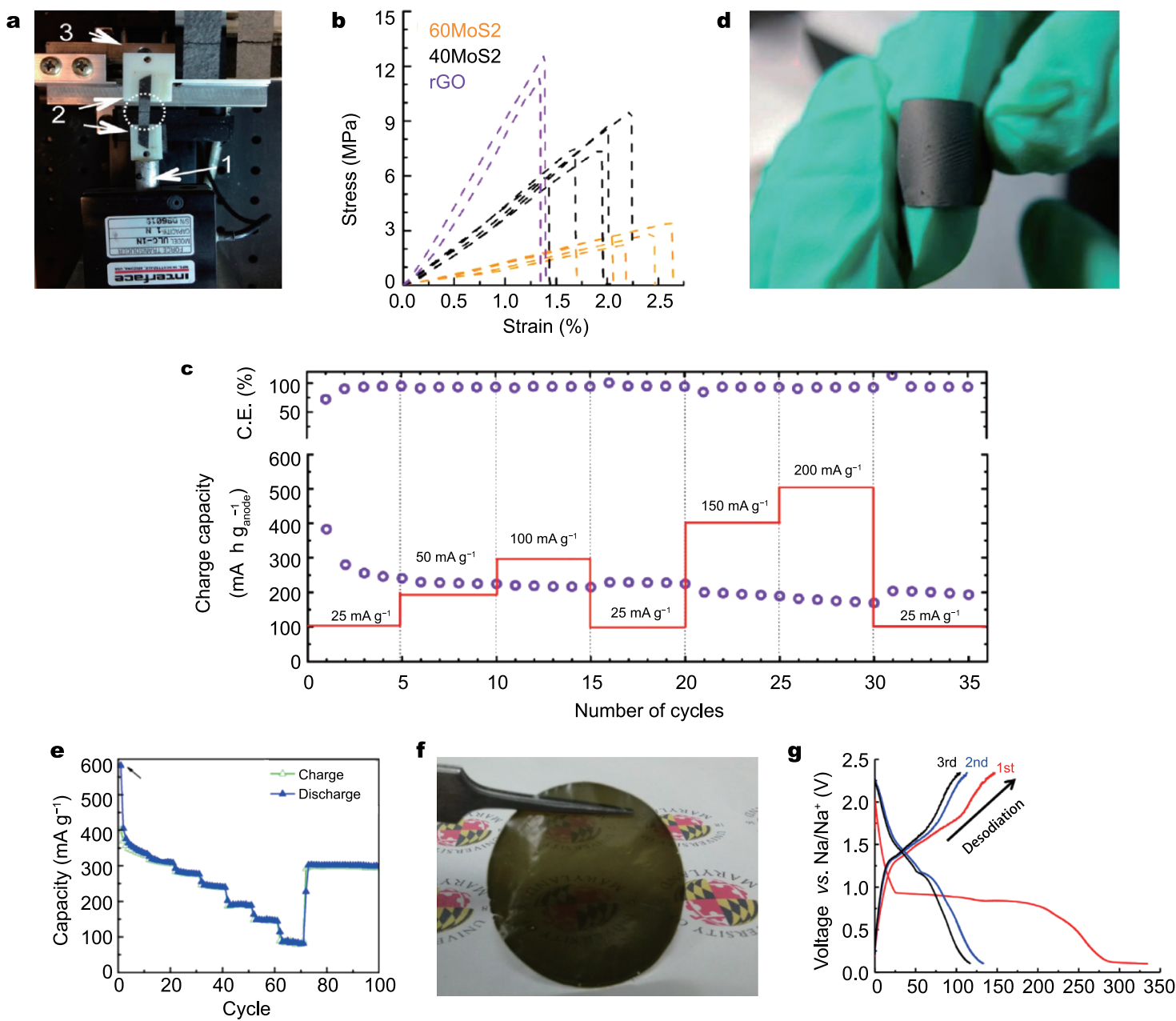

Figure 2 (a) Tensile test setup. (b) Engineering stress strain plot for $\mathrm{rGO}, 40 \mathrm{MoS}_{2}$, and $60 \mathrm{MoS}_{2}$ free-standing papers. (c) Sodium charge capacity and corresponding Coulombic efficiency of $60 \mathrm{MoS}_{2}$ electrode cycled at varying current densities. Reproduced with permission from Ref. [37]. Copyright 2014, American Chemical Society. (d) Digital photo shows the flexible property of the as-obtained $\mathrm{MoS}_{2}-\mathrm{CNFs}_{\text {film. }}$ (e) Rate capacity of the MoS ${ }_{2}$-CNFs at different current densities in the potential range of 0.01-3.0 V. Reproduced with permission from Ref. [39]. Copyright 2015, Nature Publishing Group. (f) A digital image of the $\mathrm{MoS}_{2}$ film. (g) Charge (sodiation) and discharge (desodiation) voltage profiles of the sodium ion battery for the first three cycles at $10 \mathrm{~mA} \mathrm{~g}^{-1}$ using a MoS 2 composite film as the working electrode. Reproduced with permission from Ref. [40]. Copyright 2015, Elsevier.

ing electrodes, the batteries exhibited excellent reversible capacities, superior rate capacity and outstanding cyclability (Fig. 2e). Other flexible nanocomposite membranes may also be fabricated by this present strategy for high performance binder-free electrodes serving as future flexible SIBs. In addition to $\mathrm{MoS}_{2}$, layered $\mathrm{WS}_{2}$ material has also exhibited a great deal of attentions for SIBs in these years. Owing to large volume expansions for $\mathrm{Na}^{+}$ storage, $\mathrm{WS}_{2}$ suffered from poor cycling performance. To address this problem, Choi et al. [44] prepared $\mathrm{WS}_{2}$ nanosheet-decorated three-dimensional reduced graphene oxide (3D-RGO) microspheres. When acted as anode materials for SIB, the hybrid demonstrated superior property. Another noteworthy advance in flexible SIBs was the intro- duction of nanocellulose, an aqueous solution to efficiently disperse $2 \mathrm{D}$ materials. Owing to the superior flexibility of $2 \mathrm{D} \mathrm{MoS} 2$ materials, Li et al. [40] prepared transparent freestanding $\mathrm{MoS}_{2}$ films (a thickness of $10 \mu \mathrm{m}$ ) by this method (Fig. 2f). Homogenous $\mathrm{MoS}_{2} /$ nanofibrillated cellulose (NFC)/carbon nanotubes (CNT) electrode composites were also evaluated as SIB working electrode. As a result, the first cycle discharge capacity at $10 \mathrm{~mA} \mathrm{~g}^{-1}$ was about $147 \mathrm{~mA} \mathrm{~h} \mathrm{~g}^{-1}$ in the range of $0.1-2.35 \mathrm{~V}$, which was higher than the pure $\mathrm{MoS}_{2}$ paper battery anode (Fig. 2g). Overall, the feasibility of using NFC dispersed $\mathrm{MoS}_{2}$ films is effectively demonstrated as SIB anodes for potential flexible battery applications. For the first time, Share et al. [45] prepared $\mathrm{WSe}_{2}$ as anode material for sodium storage. 
By comparing the energetics of $\mathrm{WSe}_{2}$ with $\mathrm{WS}_{2}$ electrodes, an obvious reduced overpotential of $0.26 \mathrm{~V}$ was achieved. $\mathrm{WSe}_{2}$ displayed an excellent electrochemical performance, reversible specific capacity of more than $200 \mathrm{~mA} \mathrm{~h} \mathrm{~g}^{-1}(20$ $\mathrm{mA} \mathrm{g}^{-1}$ ) and maintained $60 \%$ capacity $\left(400 \mathrm{~mA} \mathrm{~g}^{-1}\right)$. And it highlights the promising and practical SIBs application of $\mathrm{WSe}_{2}$, which predicts its potential application in flexible sodium ion storage. By further improving and optimizing the already promising performance, these newborn TMDs will have broad impact on flexible SIBs.

\section{Other batteries}

In addition to the flexible LIBs and SIBs for energy storage, there are rapid developments for flexible magnesium ion batteries [46], potassium ion batteries [47], lithium- $\mathrm{O}_{2}$ batteries [48] and lithium sulfur batteries [49] for energy storage. With the development of science and technology, it will not be long before NB2DMs materials are applied to these batteries for flexible energy storage.

As has been described above, the NB2DMs such as $\mathrm{MoS}_{2}$, $\mathrm{WS}_{2}$ and $\mathrm{BP}$ have been extensively studied for applications in flexible batteries. These materials all exhibit excellent performance in batteries, such as an enhanced specific capacity, superior cycle stability, rate capability, flexibility and so on. However, there is no doubt that the NB2DMs will have tremendous application in flexible batteries, and it will also boost the development of portable and wearable electronics.

\section{Supercapacitors}

In order to compensate for the lower power densities and relatively slow charging-discharging rates of rechargeable batteries, SCs have appeared as an alternative candidate to batteries and possess a great number of potential advantages in performance, including superior cycle life, ultrafast charging-discharging rates, and high power densities and so on. As one of the most promising energy storage devices, a new type of flexible SCs is attracting more and more attention owing to their high power density and great mechanical strength, which make them very suitable in future stretchable electronics.

The selection of active materials in SCs is significant and enormous efforts have been devoted to NB2DMs for their large field effective mobility, excellent stability, low cost and mechanical properties. Some newborn TMDs have been greatly explored in providing a huge potential for the development of flexible SCs with higher electrochemical performance.

Flexible SCs require new alternative materials with supe- rior electrochemical performance as well as excellent mechanical properties. Salvatore et al. [50] created a simple mechanically exfoliated process enabling the fabrication and transfer of few-layers $\mathrm{MoS}_{2}$ thin film transistors from silicon template to almost any other substrates, no matter organic or inorganic, flexible or rigid. They measured a mobility of $19 \mathrm{~cm}^{2} \mathrm{~V}^{-1} \mathrm{~s}^{-1}$, an $I_{\text {on }} / I_{\text {off }}$ ratio greater than $10^{6}$ and a threshold voltage of about $-2 \mathrm{~V}$ [50]. In attempting to improve the coulombic efficiency, a solid-state, flexible, asymmetric SC with good rate, cycling stability, and improved energy density was created. The asymmetric SC can still be cycled reversibly with the cell voltage up to $1.4 \mathrm{~V}$, indicating its favorable properties in storing energy. Different galvanostatic charge-discharge curves of the $\mathrm{MoS}_{2}-\mathrm{rGO} /$ multi-walled carbon nanotubes (MWCNT) SCs at charge-discharge current densities of 0.07 to $2 \mathrm{~A}$ $\mathrm{cm}^{-3}$ were shown in Fig. 3a. The asymmetric SCs can reversibly cycle with a cell voltage of $1.4 \mathrm{~V}$, while at the same time the oxidation current becomes $1.6 \mathrm{~V}$ (Fig. 3c). Inside of Fig. $3 \mathrm{c}$ was the photo of the SCs based on a glass slide. Fig. $3 \mathrm{~b}$ exhibited the images of the tightly knotted $\mathrm{MoS}_{2}$ /MWCNT and $\mathrm{rGO} / \mathrm{MWCNT}$ fibers, indicating the great flexibility of the composites [21]. In another study, Liu et al. [46] synthesized a 2D tin selenide nanostructure with a simple solvent method. The as-exhibited high electrochemical performance and specific capacitance of these materials indicated a great potential in future electronic devices, including SCs. Zhang et al. [51] fabricated a new structure with crystallographic core/amorphous shuck $\left(\mathrm{Ni}_{3} \mathrm{~S}_{4} / \mathrm{MoS}_{2}\right)$ by a one-step process. Combining the superiority of flexible amorphous shuck and great capacitance of the core, the structure showed great capacitance reservation of $90.7 \%$ after 3000 cycles at $10 \mathrm{~A} \mathrm{~g}^{-1}$. A composite membrane was made from semi-conductive $\mathrm{MoS}_{2}$ and submetallic graphene by Bissett et al. [52] and it exhibited a high electrochemical performance of great specific capacitance $\left(\sim 11 \mathrm{mF} \mathrm{cm}^{-2}\right.$ at $\left.5 \mathrm{mV} \mathrm{s}^{-1}\right)$, great energy storage property and especially excellent cycle life. Fig. 3d displayed the scanning electron microscopy (SEM) image of $\mathrm{MoS}_{2}$-graphene membrane (1:3). Fig. 3e showed the cyclic voltammograms (CVs) of the coin cells, from which we can get that the composite membrane (1:3) possessed superior capacitance compared to its individual components of $\mathrm{MoS}_{2}$ or graphene [52]. Furthermore, Feng et al. [53] synthesized a $\mathrm{VS}_{2}$ ultrathin nanosheets with less than five $\mathrm{S}-\mathrm{V}-\mathrm{S}$ atomic layers by exfoliation. The high-resolution transmission electron microscopy (HRTEM) and selected area electron diffraction (SAED) analysis of $\mathrm{VS}_{2}$ were exhibited in Fig. 3f and it indicated the great crystallinity 

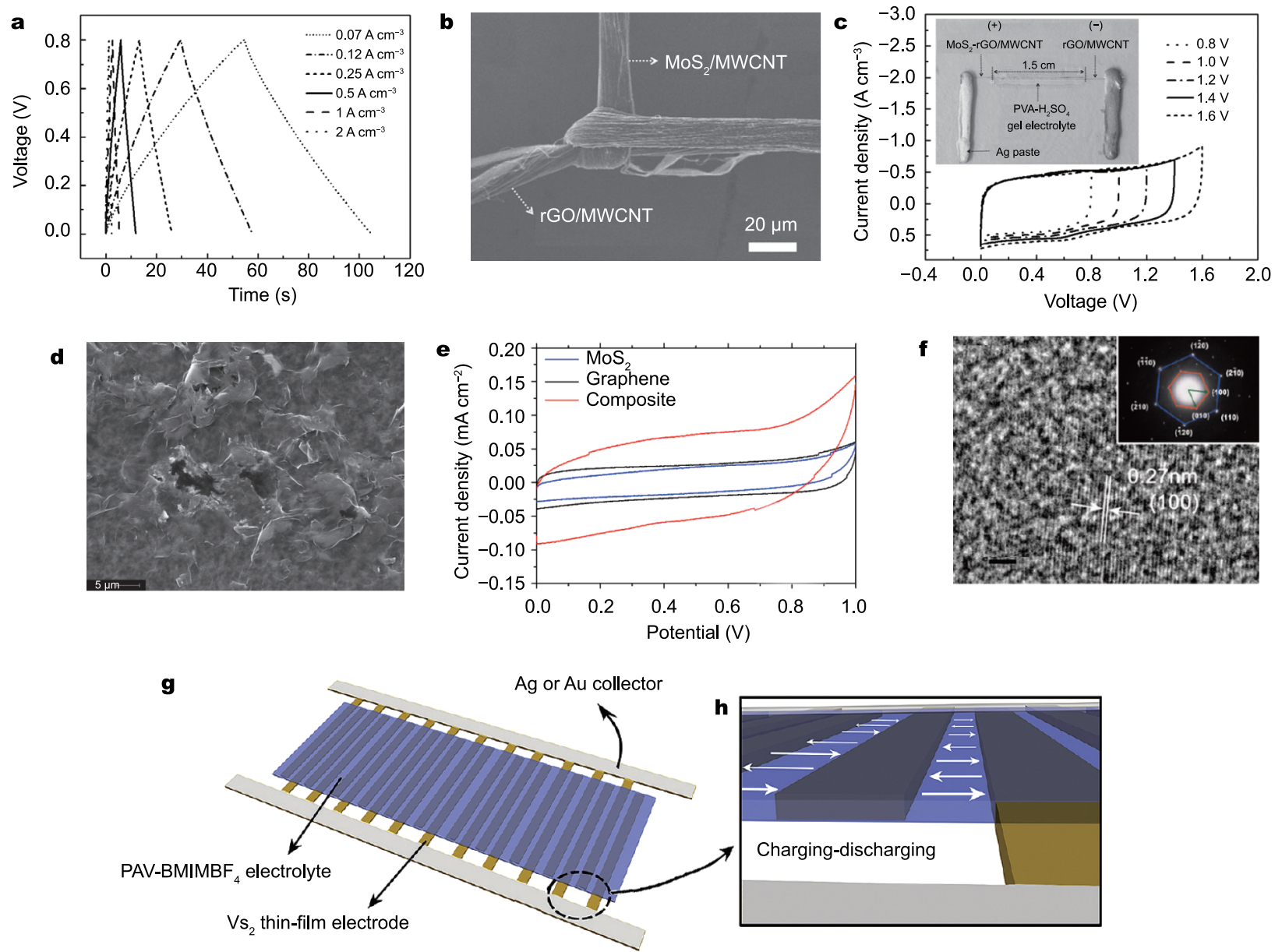

Figure 3 (a) Charge-discharge curves of the $\mathrm{MoS}_{2}-\mathrm{rGO} / \mathrm{MWCNT}$ asymmetric SC at different current densities. (b) $\mathrm{MoS} / \mathrm{MWCNT}$ and $\mathrm{rGO} / \mathrm{MWCNT}$ fibers which are tightly knotted. (c) CV of the fiber-based SC at different cell voltage. Inset: photograph of the fiber-based SC on a glass slide. Reprinted

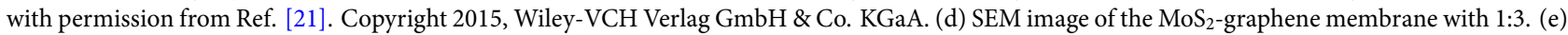
$\mathrm{CV}$ curves of the symmetric coin cells built from $\mathrm{MoS}_{2}$, graphene, and composite membranes (1:3), showing the increased capacitance of the composite film (scan rate is $50 \mathrm{mV} \mathrm{s}^{-1}$, and the electrolyte is $1 \mathrm{~mol} \mathrm{~L}^{-1} \mathrm{Na}_{2} \mathrm{SO}_{4}$ ). Reprinted with permission from Ref. [52]. Copyright 2015, American Chemical Society. (f) HR-TEM and SAED of the $\mathrm{VS}_{2}$ nanosheets. (g) Ion migration pathways of the as-obtained SC. (h) Schematic description of the in-plane structure of the SC. Reprinted with permission from Ref. [53]. Copyright 2011, American Chemical Society.

and displayed the microcosmic orientation along $c$ axis of the materials, which provided a great potential for large applied devices. Figs $3 g$ and $h$ showed the ion migration route, which provides facile channels for ion transport, and schematic of the as-made SCs. Through vacuum filtration, the bulk $\mathrm{VS}_{2}$ flakes can be reduced to a single orientated $\mathrm{VS}_{2}$ thin film with high conductivity and high specific area for forming an in-plane SCs. The devices realized a specific capacitance of $4760 \mu \mathrm{F} \mathrm{cm} \mathrm{cm}^{-2}$ in the $150 \mathrm{~nm}$ in-plane configuration and exhibited scarcely decrease after 1000 charge/discharge cycles [53].

Recently, $\mathrm{MoS}_{2}$ hierarchical nanospheres were synthesized by Javed et al. [54] via a facile hydrothermal method. In evaluating the electrochemical performance of this $\mathrm{MoS}_{2}$-based SCs, high capacitance behavior of these electrodes at a wide range of scan rates was discovered. Furthermore, they tested the electrochemical impedance spectroscopy (EIS) of the SCs by the small semicircle and it indicated a good electrical conductivity and low resistance. Meanwhile, the cycling stability was also tested and it showed only $3.5 \%$ decrease after 5000 cycles [54]. In another study, a defect-rich $\mathrm{MoS}_{2}$ ultrathin film was prepared by a simple hydrothermal method. Due to its adequate unsaturated sulfur atoms, the as-constructed SCs exhibited unique electrochemical properties, such as high specific capacitance retention ratio, great power density and especially the cycling stability [55]. For further enhancing the cycling stability, self-supporting 3D $\mathrm{MoS}_{2} / \mathrm{Ni}(\mathrm{OH})_{2}$ 
nanocomposites were synthesized via a simple microwave hydrothermal technique. The SCs based on the nanocomposites exhibited excellent long-time cycling stability that reserving $94.2 \%$ of the initial capacitance after 9000 cycles, and it still kept high capacitance of $14.07 \mathrm{mF} \mathrm{cm}^{-2}$ after the cycling. Therefore, this superb structure can have an application prospect for small, light-weight and flexible electronic devices [56]. Ratha et al. [57] synthesized a layer construction of $\mathrm{WS}_{2} / \mathrm{RGO}$ hybrids, considering its probable prospect as SC materials. They tested its electrochemical properties by using $\mathrm{CV}$ and charge-discharge cycles. The hybrids showed greatly enhanced capacitance of $350 \mathrm{~F} \mathrm{~g}^{-1}$, higher than RGO and $\mathrm{WS}_{2}$ sheets of 130 and $70 \mathrm{~F} \mathrm{~g}^{-1}$ [57]. WSe $e_{2}$ can also be prepared for construction of SC, Chakravarty et al. [58] used a microwave methods to prepare $\mathrm{WSe}_{2}$-based unique structure, and its cycling stability and charging-discharging performance are greater than commonly prepared ones [58].

As discussed above, several TMDs have been widely investigated. All of them showed a remarkable performance for flexible SCs, such as high capacitance, cycling stability, great conductivity, power density, stretchability and so on. Therefore, we have faith to believe that NB2DMs-based high performance flexible SCs will bring about drastic advances in technology and play a vital role in flexible electronics.

\section{FLEXIBLE DEVICES RELATED TO ENERGY CONVERSION}

The as-exhibited unique optoelectronic properties of the NB2DMs make them become the promising candidates for optoelectronic applications such as solar cells and photodetectors. NB2DMs-based hydrogen evolution devices and NGs possess good flexibility and promising performances, which are induced by their highly reactive edge sites and good electrical conductivity. The recent achievements of the devices related to energy conversion are discussed in the following section.

\section{Optoelectronic devices}

Flexible optoelectronic devices are mechanically stable electronics that can generate, detect, interact with or control light. NB2DMs with direct band gaps in the visible portion of the electromagnetic spectrum [12], large exciton binding energies [59], and strong photoluminescence [60] become the promising candidates for optoelectronic applications such as solar cells and photodetectors. Meanwhile, benefiting from their 2D geometry, those materials exhibit high compatibility with various fabrication methods such as chemical vapor deposition (CVD) [61] and it makes them very suitable to construct the flexible optoelectronic devices on the flexible substrates via direct growth or transferring.

\section{Solar cells}

A solar cell is an electrical device that converts the solar energy, which is renewable and green, directly into electricity via the photovoltaic effect. A range of flexible solar cells have been developed by utilizing the solar energy, which is one of the most abundant renewable energy. Those devices are built on $\mathrm{p}-\mathrm{n}$ junctions or heterojunctions to produce electricity via the photovoltaic effect. Upon the illumination of light, the electron-hole pairs or free carriers of the active layers could be generated by the incident photons and photocurrent at the p-n junctions is generated. The extraordinary optoelectronic properties of NB2DMs such as efficient light absorption and direct band gap make them the permit building blocks of solar cells [62-70].

Solar cells constructed by NB2DMs-based structures of other dimensions, such as pillar, wire and dot, have already been studied. Fan et al. [70] reported a photovoltaic structure where single-crystalline $\mathrm{n}$-CdS nanopillar arrays were embedded in polycrystalline thin films of p-CdTe. Highly periodic anodic alumina membranes (AAMs) formed on aluminum foil substrates were utilized as the template to prepare the single-crystalline nanopillar. An SEM image of as-synthesized structures was shown in Fig. 4a. After AAMs were partially etched away, a $1 \mu \mathrm{m}$ photoabsorption layer of p-type CdTe was then deposited via a CVD process. A bendable solar cell was realized via utilizing polydimethylsiloxane (PDMS) as a support substrate (inset of Fig. 4b). Compared with planar structures, photoelectrodes based on CdSe nanopillar arrays could exhibit enhanced collection of low-energy photons. Therefore, an enhanced carrier collection efficiency was realized utilizing this nanopillar-array structure and the performance characterization of the as-prepared flexible solar cell was exhibited in Fig. 4b. The 2D monolayers of semiconducting (TMDs) possess direct band gaps and could absorb up to $5-10 \%$ of sunlight, which is one order of magnitude higher than that absorbed by GaAs or Si of the same thickness. However, the power-conversion efficiency (PCE) of the TMDC stack is only $1-2 \%$, which is significantly lower than that of GaAs and Si [9]. Therefore, solar cells based on a heterojunction between monolayer $\mathrm{MoS}_{2}$ and $\mathrm{p}$-Si were created to achieve a higher PCE [68]. Cr/Ag layers were deposited on the p-type Si substrate, which removed the native oxide layer, as the back electrode. Monolayer $\mathrm{MoS}_{2}$ 
a

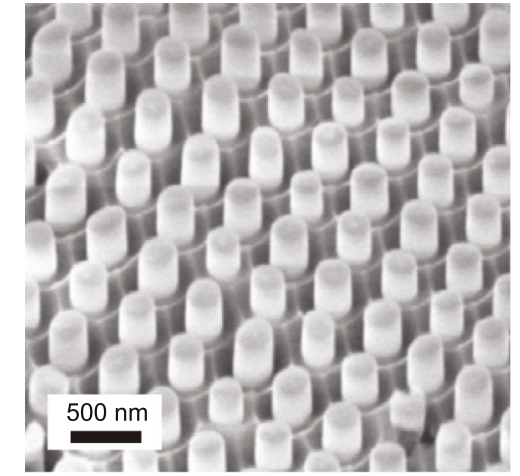

c

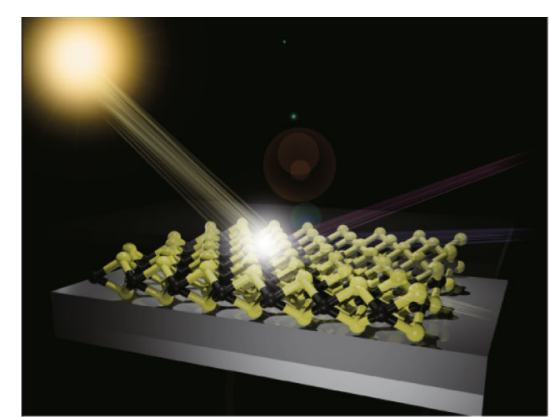

b
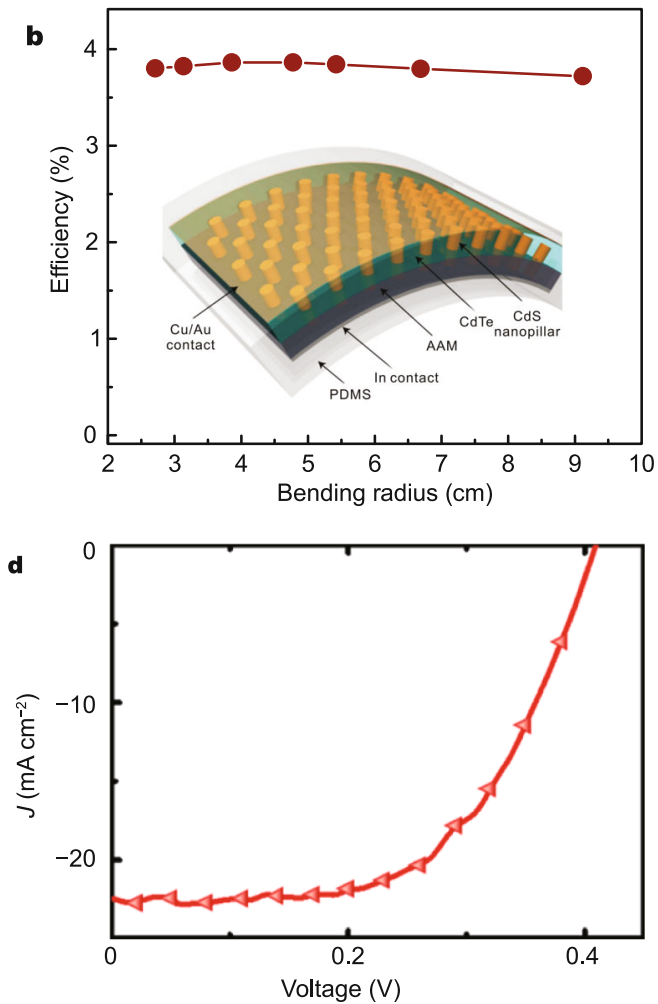

Figure 4 (a) The SEM image of CdS nanopillar array after partial etching of the AAM. (b) The performance characterization of a flexible solar cell based on CdS nanopillar array and inset is the schematic diagram of the device. Reprinted with permission from Ref. [70]. Copyright 2009, Nature Publishing Group. (c) Schematic illustration of the solar cell based on $\mathrm{MoS}_{2} / \mathrm{p}-\mathrm{Si}$ heterojunction and (d) J-V characteristics of the device. Reproduced with permission from Ref. [68]. Copyright 2014, American Chemical Society.

was then transferred on the top of the substrate and a thin Al layer was deposited as the top electrode to facilitate carrier collection via creating an ohmic contact with the $\mathrm{MoS}_{2}$ monolayer (Fig. 4c). The J-V characteristics of the $\mathrm{MoS}_{2} / \mathrm{p}$-Si heterojunction solar cell was exhibited and a PCE of 5.23\% was achieved (Fig. 4d). This work indicated that monolayer TMDs based heterojunctions could be the promising candidates of high-PCE solar cells. In addition, a strain induced effect could offer a new strategy to improve the solar energy conversion efficiency of a flexible solar cell. Pan et al. [63] reported the work of enhanced performance of $\mathrm{n}-\mathrm{CdS} / \mathrm{p}-\mathrm{Cu}_{2} \mathrm{~S}$ coaxial nanowire bendable solar cells via piezo-phototronics effect. The p-n homojunctions are a kind of structures which are constructed by two same semiconductors with opposite conduction types. Compare to heterojunctions, photovoltaic devices based on $\mathrm{p}-\mathrm{n}$ homojunctions performed superior optoelectronic properties due to the perfect band alignment and negligible lattice mismatching. Shao et al. [69] reported a study of flexible photovoltaic devices based on CdS p-n homojunction. CdS nanoribbons (NRs) p-n homojunctions could be constructed by selectively decorating the NRs with $\mathrm{MoO}_{3}$ nanodots (NDs) at defined area and the as-based flexible photovoltaic devices exhibited high PCE value of 5.48\%.

\section{Photodetectors}

Photodetectors are energy conversion electronics that can convert light signals to electric signals. Therefore, those devices could be applied in various practical applications like imaging, communication devices and various sensors for safety monitoring and possess significant importance in our daily life. The basic theory of photodetectors is similar to that of photovoltaic devices. Upon the excitation of light, the bound electron-hole pairs are generated by the incident photons whose energy is greater than the band gap of the semiconductor and the yielded photocurrent is correlated with light intensity [15]. Compared to silicon with an indirect band gap or graphene without a band gap [59], NB2DMs with tunable direct band gap and high absorption efficiency have emerged as potential candidates for next-generation flexible photodetectors [22,71-84].

Monolayer $\mathrm{MoS}_{2}$, as one of the typical semiconductor with a direct band gap from the TMDs family, could be a promising material for photodetectors where the direct 
band gap would allow a high absorption coefficient and efficient electron-hole pair generation under photoexcitation. Lopez-Sanchez et al. [22] reported a work for ultrasensitive monolayer $\mathrm{MoS}_{2}$ photodetector (Fig. 5a) with a photoresponsivity of $880 \mathrm{~A} \mathrm{~W}^{-1}$ (Fig. 5b), which is about six order of magnitudes higher than the previous report for monolayer graphene. This improvement was mainly induced by the direct band gap. In addition, the presence of a band gap and the high degree of electrostatic control could induce to a low dark current, which makes the monolayer $\mathrm{MoS}_{2}$-based photodetectors can be turned off. However, the devices suffered an intrinsic limitation of slow photoresponse dynamics and the resulted response time is long as 4 s. Chen et al. [73] reported the study of flexible photodetectors based on ultrathin $\mathrm{Bi}_{2} \mathrm{~S}_{3}$ nanosheets (Fig. $5 \mathrm{c}$ ) and the devices exhibited relatively fast response time as $10 \mu$ s (Fig. $5 \mathrm{~d}$ ). The bulk direct band gap of $1.3 \mathrm{eV}$ and large absorption coefficient of $\mathrm{Bi}_{2} \mathrm{~S}_{3}$ makes it a promising active material of broadband photodetectors. The fast response time can be attributed to the contact quality and intrinsic properties of the active layer. The $\mathrm{Bi}_{2} \mathrm{~S}_{3}$ nanosheets performed in the devices were synthesized from the reaction of triphenyl
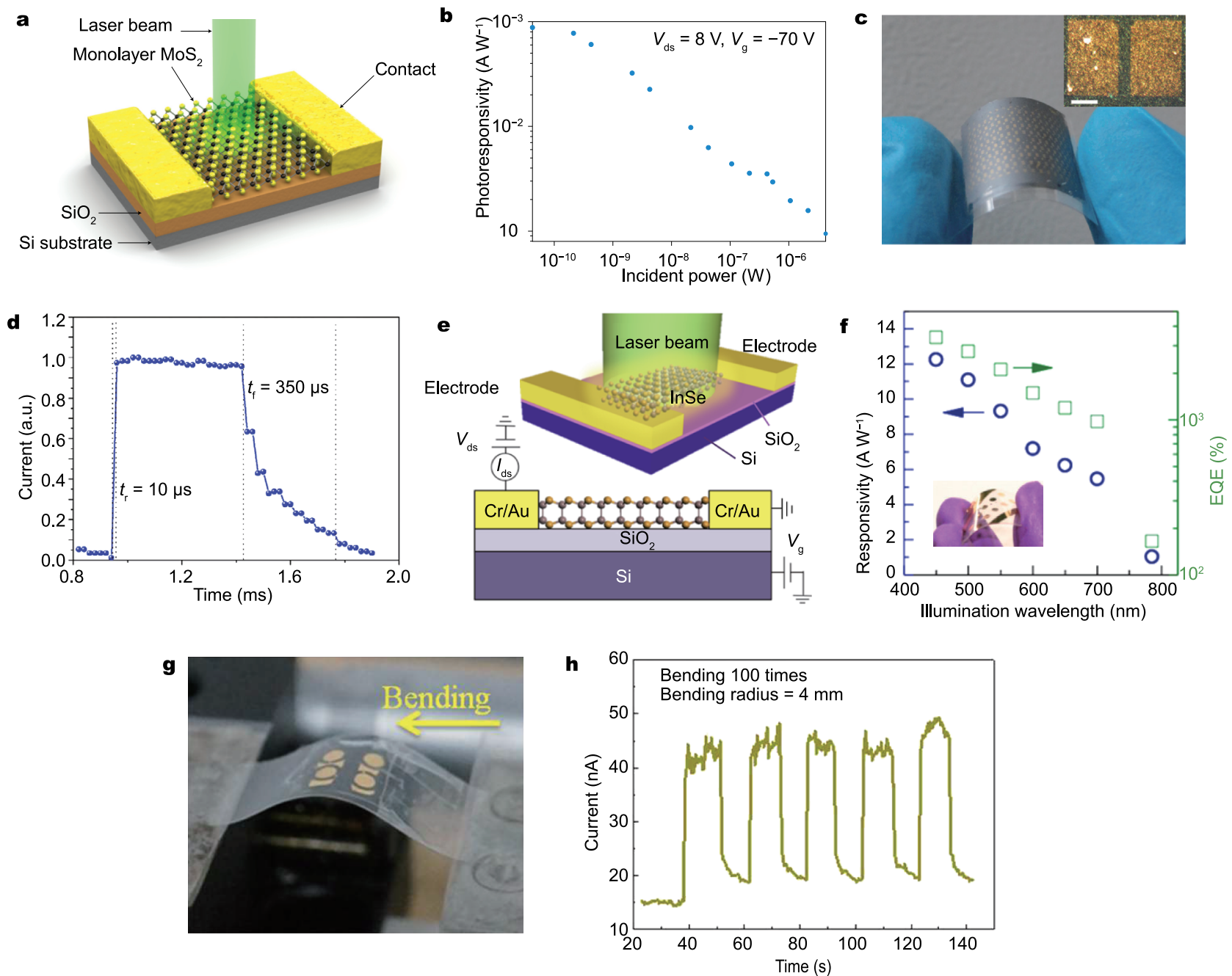

Figure 5 (a) 3D schematic view of the single-layer $\mathrm{MoS}_{2}$ photodetector and (b) the photoresponsivity of the device, showing high sensitivity. Reproduced with permission from Ref. [22]. Copyright 2014, Nature Publishing Group. (c) Photograph of the flexible device based on $2 \mathrm{D} \mathrm{Bi}_{2} \mathrm{~S}_{3}$ nanostructures and micrograph of a typical device (inset). (d) The magnified plots of one response cycle for demonstrating the response time. Reproduced with permission from Ref. [73]. Copyright 2015, Wiley-VCH Verlag GmbH \& Co. KGaA. (e) The schematic illustrations of a few layer InSe-based photodetector and (f) the spectral responsivity and calculated external quantum efficiency (EQE) of the device illuminated at $450-785 \mathrm{~nm}$. Inset is a digital image of the as-fabricated flexible device on PET. Reproduced with permission from Ref. [78]. Copyright 2014, American Chemical Society. (g) Photograph of the instrument used for bending and the picture of the flexible device based on $2 \mathrm{D} \mathrm{Pb}_{1-\mathrm{x}} \mathrm{Sn}_{\mathrm{x}} \mathrm{Se}$. (h) Time trace of photoresponse bending the device for 100 times. Reproduced with permission from Ref. [84]. Copyright 2015, American Chemical Society. 
bismuth with dibenzyl disulfide and a thickness down to $2.2 \mathrm{~nm}$ was achieved for the first time. Meanwhile, the $\mathrm{Bi}_{2} \mathrm{~S}_{3}$ nanosheets-based bendable photodetectors were fabricated on the polyethylene terephthalate (PET) substrates via a facile drop-deposition process. The as-prepared device showed excellent photoresponse properties with a responsivity of $4.4 \mathrm{~A} \mathrm{~W}^{-1}$.

Photodetection range is another crucial index to evaluate the performance of photodetectors [75]. InSe exhibits stronger quantum confinement compared to those of the other group IIIA-VIA family due to its narrower band gap and smaller exciton reduced mass. This makes it possible to achieve the controllability of the band gap of the constructing materials for the spectrally tunable devices. Thus, broadband photodetection from the visible to nearinfrared region (450-785 $\mathrm{nm}$ ) with high photoresponsivities of $\sim 12.3 \mathrm{~A} \mathrm{~W}^{-1}$ was achieved by few layer InSe-based photodetectors [78]. Flexible devices were also fabricated utilizing PET substrates and exfoliated InSe samples (Fig. 5e). The photoresponsivity and photoswitching stability of the devices were performed well before and after bending and the measured data were comparable to the value of the devices on the $\mathrm{SiO}_{2} / \mathrm{Si}$ substrates (Fig. 5f). Meanwhile, the few-layered InSe photodetectors also exhibited long-termstable photoswitching performance. $\mathrm{Pb}_{1-x} \mathrm{Sn}_{x} \mathrm{Se}$, a kind of topological crystalline insulators with a narrow band gap $(0.43 \mathrm{eV})$, was utilized to construct photodetectors with bored spectra response, which is ranging from ultraviolet (UV) to infrared light $(375,473,632,800$, and $980 \mathrm{~nm})$ [84]. The growth of $\mathrm{Pb}_{1-x} \mathrm{Sn}_{x} \mathrm{Se}$ nanoplates with a thickness of $\sim 15-45 \mathrm{~nm}$ were realized by van der Waals epitaxy (vdWE) strategy on mica sheets. Flexible photodetectors were then fabricated (Fig. 5g) and the as-prepared devices exhibited fast, stable, and reversible photoresponse even after being bent for 100 times (Fig. 5h). It indicated that $2 \mathrm{D} \mathrm{Pb}_{1-x} \mathrm{Sn}_{x} \mathrm{Se}$-based photodetectors on mica sheets possess great potential in flexible and wearable optoelectronic applications. We believe that further exploration of various NB2DMs is of great significance to be executed to the performance of flexible optoelectronic devices.

\section{Hydrogen evolution}

Over use of fossil fuels has a significant influence on air pollution and global warming. Therefore, developing a clean, renewable alternative energy source to replace fossil fuels is in urgent need. Among the multifarious energy strategies, fabricating a universal flexible energy structure where hydrogen is employed as the energy source can bring about a cleaner energy future. An applicable method of $\mathrm{H}_{2}$ produc- tion is the electrolysis of water. In this way, this reaction requires catalysts to reduce the overpotential (the difference between the applied potential and thermodynamic potential of a given electrochemical reaction). Beyond the most efficient catalysts like platinum group metals, non-noble metal compounds are abundant on earth, such as TMDs. They have been widely used in the past decade owing to their high specific surface area and electronic properties. Therefore, making full use of them in hydrogen evolution reaction (HER) is significant in meeting the energy consumption present at a large scale. Highly active and flexible inexpensive hydrogen evolution catalysts are required to make the water splitting process more efficient, economical and nimble.

To make the HER perform better, Zhang et al. [85] reported the controllable synthesis of arborescent, transferable and rigid monolayer $\mathrm{MoS}_{2}$ on $\mathrm{SrTiO}_{3}$ by CVD method. Then the $\mathrm{MoS}_{2}$ layers with different coverage and domain sizes were transferred to Au foils for HER activity testing. As expected, Tafel slope reached $73 \mathrm{mV} /$ decade, which is lower than the previous one grown on glassy carbon electrodes. With rapidly increasing demand, an edge-oriented $\mathrm{MoS}_{2}$ film was obtained by reaction of sulfur with Mo oxide sponge, as shown in Fig. 6a. After reacting with sulfur, the color of Mo foil becomes gray, meanwhile, the $\mathrm{MoS}_{2}$ on the Mo foils shows great flexibility (Fig. 6b). Excellent activity and long-time cycling stability were shown in the HER measurement. Fig. $6 \mathrm{c}$ indicated the optimal annealing time for edge-oriented $\mathrm{MoS}_{2}$ films and it can be concluded that too long or too short annealing time will lead to an improper overpotential [86]. Compared to $\mathrm{MoS}_{2}$, cobalt sulfides have been employed as an efficient catalysts in oxygen reduction reactions (ORR). Peng et al. [87] prepared a conductive, flexible and ropy $\mathrm{CoS}_{2} / \mathrm{rGO}-\mathrm{CNT}$ nanostructure for its potential use in wearable electronics. Fig. $6 \mathrm{~d}$ showed a schematic graph of the prepared $\mathrm{CoS}_{2} / \mathrm{rGO}-\mathrm{CNT}$ film. The obtained film with unique 3D structures exhibited excellent HER performance with a Tafel slope of about $51 \mathrm{mV} /$ decade. From Fig. 6e we can get the information that the composite film showed better HER properties than bare $\mathrm{CoS}_{2}$ or $\mathrm{CoS}_{2} / \mathrm{rGO}$. (The bare $\mathrm{CoS}_{2}$ and $\mathrm{CoS}_{2} / \mathrm{rGO}$ were tested based on glassy carbon electrodes, and all samples were tested in a $0.5 \mathrm{~mol} \mathrm{~L}^{-1} \mathrm{H}_{2} \mathrm{SO}_{4}$ ). Moreover, TMDs are also used for solar hydrogen production, for example, Benck et al. [88] designed a structure of silicon photocathodes loaded by $\mathrm{MoS}_{2}$ nanomaterials. In this study, they found that $\mathrm{MoS}_{2}-\mathrm{n}^{+} \mathrm{p}$ Si photocathode structure showed the onset potential of $-0.25 \mathrm{~V} v s$. RHE and great durability of more than $24 \mathrm{~h}$. In another work, a new composite film 
of $\mathrm{MoSe}_{2}-\mathrm{rGO} /$ polyimide was synthesized. Then the photoelectric properties was tested and a special behavior different from other HER catalysis was exhibited. It had a photo-free character whether in dark or irradiation. A favorable effect and good stability of the devices were shown. After 100 cycles, it still kept a Tafel slope of $82 \mathrm{mV}$ per dec [89]. $\mathrm{Mo}_{2} \mathrm{C}$, as a new two-dimensional material, also have been studied as the solar hydrogen production catalyst. Fig. $6 f$ displayed the SEM image of the photocathode based on $\mathrm{Mo}_{2} \mathrm{C}$, where different layers were visible.
The photocathode exhibited high activity and good stability both in $\mathrm{H}_{2} \mathrm{SO}_{4}$ and $\mathrm{KOH}$, as shown in Fig. $6 \mathrm{~g}$ and h. The performance was superior to that of $\mathrm{W}_{2} \mathrm{C}$ deposited on $\mathrm{c}-\mathrm{Si}$ photocathodes and was only to support the Pt catalyst [90].

\section{Nanogenerators}

NGs based on nanoscale materials have so far been developed for effective power generation. This device has the potential to largely improve the capability of mechanical energy harvesting with compact designs, which might
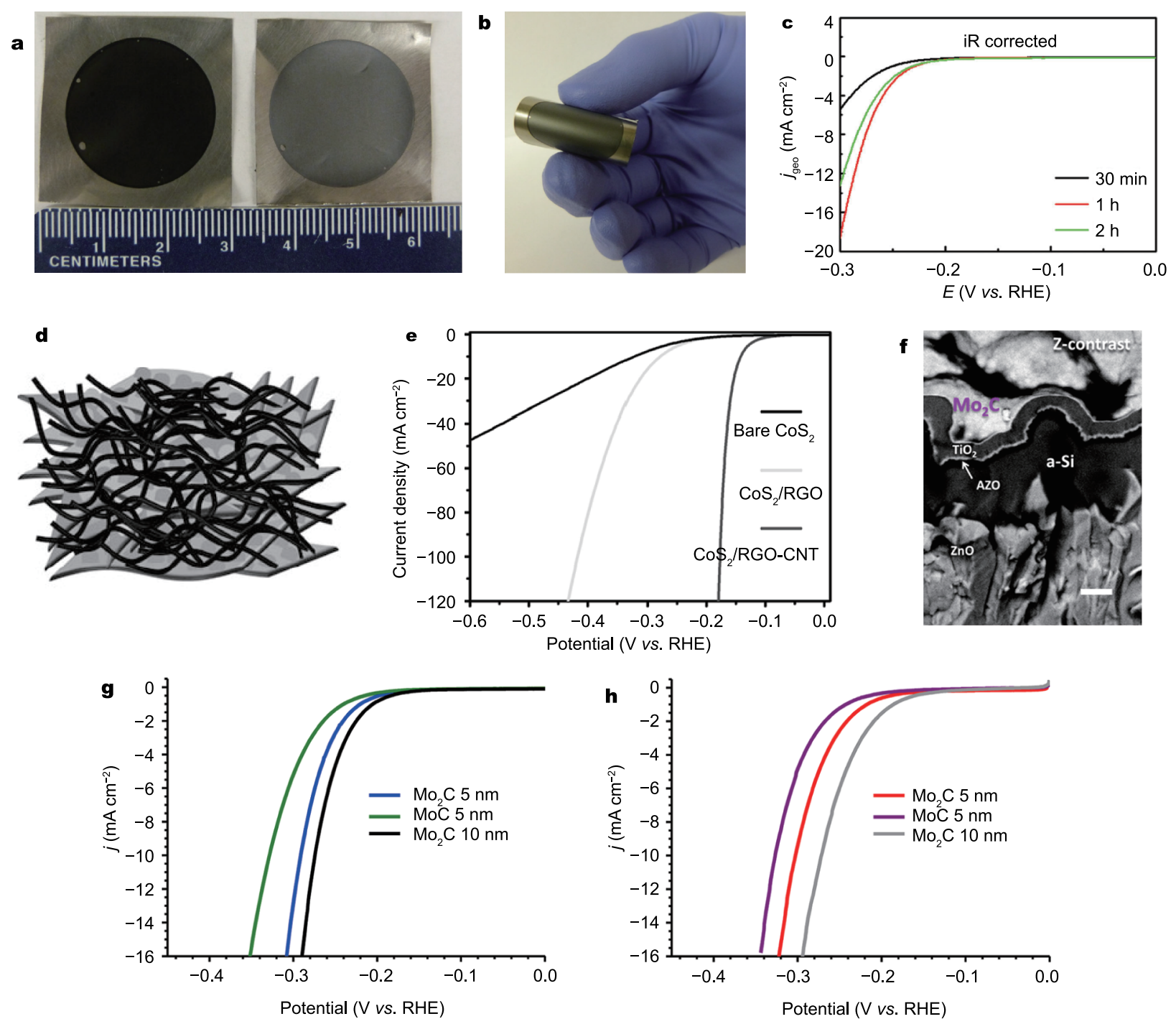

Figure 6 (a) Photos of the obtained electrodes. It shows the obvious difference between the Mo oxide (left) and $\mathrm{MoS}_{2}$ (right). (b) Photograph showing the flexibility of the as-obtained edge-oriented $\mathrm{MoS}_{2}$ film. (c) Polarization curves of the $\mathrm{MoS}_{2}$ films for different time durations (at $5 \mathrm{mV} \mathrm{s}{ }^{-1}, 300^{\circ} \mathrm{C}$ ). Reprinted with permission from Ref. [86]. Copyright 2014, WILEY-VCH Verlag GmbH \& Co. KGaA. (d) Image of CoS $2 / \mathrm{RGO}^{-C N T}$ flexible film. (e) Polarization curves of the bare $\mathrm{CoS}_{2}, \mathrm{CoS}_{2} / \mathrm{RGO}$ on glassy carbon electrodes and the $\mathrm{CoS}_{2} / \mathrm{RGO}-\mathrm{CNT}$ composite film electrodes (in $0.5 \mathrm{~mol} \mathrm{~L}^{-1} \mathrm{H}_{2} \mathrm{SO}_{4}$ ). Reprinted with permission from Ref. [87]. Copyright 2014, WILEY-VCH Verlag GmbH \& Co. KGaA. (f) SEM image of the acquired a-Si photocathode. Polarization curves of $\mathrm{Mo}_{2} \mathrm{C}$ and $\mathrm{MoC}$ catalyst films which were sputtered onto FTO in (g) $0.1 \mathrm{~mol} \mathrm{~L}^{-1} \mathrm{H}_{2} \mathrm{SO}_{4}$ and (h) 1 mol L $\mathrm{L}^{-1} \mathrm{KOH}$ respectively (scan rate of $5 \mathrm{mV} \mathrm{s}^{-1}$ ). Reprinted with permission from Ref. [90]. Copyright 2015, American Chemical Society. 
eventually lead to an effective power supply for self-powered systems with much higher energy density and efficiency, longer lifetime as well as lower cost. With the rapid development of technology, there are so many convenient and wearable electronic devices, such as flexible circuitries, pliable sensors, stretchable displays, epidermal electronics and implantable devices. So the demands for flexible and efficient energy harvesting and storage devices have increased. Herein, a new age of electronics should be invented with appropriate shapes as well as maintaining the high-performance of the device. Taking this into consideration, there are so many difficulties proposed in front of us, such as a sustainable power source supply, obbligato wire connections and convenient operations. An efficient way to solve the difficulties is to integrate NB2DMs with a power generator to scavenge the environmental energy, especially for the mechanical energy from stretching motions. There have been so many groups made their attempts to develop flexible and stretchable power generators. However, the output performances of the devices still need further enhancement for practical applications.

Wu et al. [91] had first synthesized a piezoelectric NG with a single-atomic-layer $\mathrm{MoS}_{2}$ in 2014, which exhibited the piezoelectric properties and energy conversion efficiency of $2 \mathrm{D} \mathrm{MoS}$. They used a mechanically exfoliated method to prepare $\mathrm{MoS}_{2}$ flakes and then tested its piezoelectric response via acting the strain on the device. Then, they found that polarization charges can push the electrons flow in circuit external at the edges of the sample. Furthermore, they discovered the relationship between the layer of $\mathrm{MoS}_{2}$ and piezoelectric signal. They found that no signal was detected when the atomic layer was even number or bulk, but a strong second-harmonic generation (SHG) intensity was detected when the atomic layer number is odd. Finally, they constructed an array of single-layer $\mathrm{MoS}_{2}$ flakes for energy conversion device. No matter the flakes were connected in series or in parallel, the array can lead to an enhancement to the output voltages or currents [91]. In conclusion, flexible NGs can be a reliable and stable power source for flexible device. Although not much progress has been made in this field, we believe that the introduction of NB2DMs can promote its development greatly.

\section{SUMMARY AND OUTLOOK}

We have briefly reviewed the recent progress in the nextgeneration flexible energy storage and conversion systems based on the NB2DMs. This category of atomic-scale materials exhibited excellent mechanical stability, novel optoelectronic properties, high theoretical specific capacity and power density. Therefore, they had been attracting tremendous attention in multidisciplinary subjects related to flexible energy conversion and storage processes. In this minireview, the main part was devoted to introducing recent studies on the applications in flexible energy conversion devices including solar cells, photodetectors, fuel cells, hydrogen evolution devices and NGs, and those energy storage devices including SCs and batteries. One can find that the NB2DMs with unique features beyond the main properties (specific capacity for batteries or band gaps for optoelectronic devices) can attract more attention of the researchers, which can lead to the construction of devices for special purpose, e.g., $\mathrm{WSe}_{2}$ can be employed as the anode material of SIBs to realize an obvious reduced overpotential. Therefore, discovering the unique NB2DMs and applying them to the proper devices will be one of the most familiar ways that possess great potential in the near future. One of the powerful evidences is that the extremely weak van der waals coupling of $\mathrm{ReS}_{2}$ can construct a high-current-density LIB. [17] However, there are still many challenges to be addressed for realizing it. For example, developing 2D materials with both high electric conductivity and optoelectronic performance remains a challenge. Fabricating composites with high-conductivity graphene is still required for those materials to be applied in batteries or SCs. Hence, to explore novel NB2DMs with desirable optoelectronic properties (e.g., tunable direct band gaps), high theoretical specific capacity and good conductivity are of great significance to overcome the limitations of nowaday wearable devices. We believe that it can promote the practical applications of the flexible energy devices and the systems will emerge to our daily life accompanying with the technological breakthroughs in material production and device design. To sum up, NB2DMs pave a new way for the construction of next-generation flexible energy devices with improved performance and we believe the related applications will be seen in our daily lives and improve our lifestyle.

Received 22 April 2016; accepted 9 May 2016; published online 13 June 2016

1 Lu X, Xia Y. Electronic materials: buckling down for flexible electronics. Nat Nanotechnol, 2006, 1: 163-164

2 Gelinck GH, Huitema HE, van Veenendaal E, et al. Flexible active-matrix displays and shift registers based on solution-processed organic transistors. Nat Mater, 2004, 3: 106-110

3 LeMieux MC, Bao Z. Flexible electronics: stretching our imagination. Nat Nanotechnol, 2008, 3: 585-586

4 Wang X, Shi G. Flexible graphene devices related to energy conversion and storage. Energy Environ Sci, 2015, 8: 790-823

5 Zhou G, Li F, Cheng HM. Progress in flexible lithium batteries and future prospects. Energy Environ Sci, 2014, 7: 1307-1338

6 Gwon H, Hong J, Kim H, et al. Recent progress on flexible lithium 
rechargeable batteries. Energy Environ Sci, 2014, 7: 538-551

7 Li L, Wu Z, Yuan S, Zhang XB. Advances and challenges for flexible energy storage and conversion devices and systems. Energy Environ Sci, 2014, 7: 2101-2122

8 Wang $\mathrm{X}, \mathrm{Lu} \mathrm{X}, \mathrm{Liu} \mathrm{B}$, et al. Flexible energy-storage devices: design consideration and recent progress. Adv Mater, 2014, 26: 4763-4782

9 Peng B, Ang PK, Loh KP. Two-dimensional dichalcogenides for light-harvesting applications. Nano Today, 2015, 10: 128-137

10 Novoselov KS, Geim AK, Morozov SV, et al. Two-dimensional gas of massless Dirac fermions in graphene. Nature, 2005, 438: 197-200

11 Park CM, Sohn HJ. Black phosphorus and its composite for lithium rechargeable batteries. Adv Mater, 2007, 19: 2465-2468

12 Wang QH, Kalantar-Zadeh K, Kis A, et al. Electronics and optoelectronics of two-dimensional transition metal dichalcogenides. Nat Nanotechnol, 2012, 7: 699-712

13 Zhang G, Liu H, Qu J, Li J. Two-dimensional layered $\mathrm{MoS}_{2}$ : rational design, properties and electrochemical applications. Energy Environ Sci, 2016, 9: 1190-1209

14 Wang H, Feng H, Li J. Graphene and graphene-like layered transition metal dichalcogenides in energy conversion and storage. Small, 2014, 10: 2165-2181

15 Jariwala D, Sangwan VK, Lauhon LJ, et al. Emerging device applications for semiconducting two-dimensional transition metal dichalcogenides. ACS nano, 2014, 8: 1102-1120

16 Miao YE, Huang Y, Zhang L, et al. Electrospun porous carbon nanofiber@ $\mathrm{MoS}_{2}$ core/sheath fiber membranes as highly flexible and binder-free anodes for lithium-ion batteries. Nanoscale, 2015, 7: 11093-11101

17 Zhang Q, Tan S, Mendes RG, et al. Extremely weak van der Waals coupling in vertical $\mathrm{ReS}_{2}$ nanowalls for high-current-density lithium-ion batteries. Adv Mater, 2016, 28: 2616-2623

18 Castellanos-Gomez A, Poot M, Steele GA, et al. Elastic properties of freely suspended $\mathrm{MoS}_{2}$ nanosheets. Adv Mater, 2012, 24: $772-775$

19 Liu K, Yan Q, Chen M, et al. Elastic properties of chemical-vapor-deposited monolayer $\mathrm{MoS}_{2}, \mathrm{WS}_{2}$, and their bilayer heterostructures. Nano Lett, 2014, 14: 5097-5103

20 Yang L, Wang S, Mao J, et al. Hierarchical $\mathrm{MoS}_{2} /$ polyaniline nanowires with excellent electrochemical performance for lithium-ion batteries. Adv Mater, 2013, 25: 1180-1184

21 Sun G, Zhang X, Lin R, et al. Hybrid fibers made of molybdenum disulfide, reduced graphene oxide, and multi-walled carbon nanotubes for solid-state, flexible, asymmetric supercapacitors. Angew Chem Int Ed, 2015, 54: 4651-4656

22 Lopez-Sanchez O, Lembke D, Kayci M, et al. Ultrasensitive photodetectors based on monolayer $\mathrm{MoS}_{2}$. Nat Nanotechnol, 2013, 8: 497-501

23 Balogun MS, Qiu W, Jian J, et al. Vanadium nitride nanowire supported $\mathrm{SnS}_{2}$ nanosheets with high reversible capacity as anode material for lithium ion batteries. ACS Appl Mater Interfaces, 2015, 7: 23205-23215

24 Chen Y, Song B, Tang X, et al. Ultrasmall $\mathrm{Fe}_{3} \mathrm{O}_{4}$ nanoparticle/ $\mathrm{MoS}_{2}$ nanosheet composites with superior performances for lithium ion batteries. Small, 2014, 10: 1536-1543

25 Liu Y, Wang W, Wang Y, Peng X. Homogeneously assembling likecharged $\mathrm{WS}_{2}$ and $\mathrm{GO}$ nanosheets lamellar composite films by filtration for highly efficient lithium ion batteries. Nano Energy, 2014, 7: $25-32$

26 Chen L, Zhou G, Liu Z, et al. Scalable clean exfoliation of highquality few-layer black phosphorus for a flexible lithium ion bat- tery. Adv Mater, 2016, 28: 510-517

27 Wang R, Xu C, Sun J, et al. Heat-induced formation of porous and free-standing $\mathrm{MoS}_{2} / \mathrm{GS}$ hybrid electrodes for binder-free and ultralong-life lithium ion batteries. Nano Energy, 2014, 8: 183-195

28 Du Y, Zhu X, Si L, et al. Improving the anode performance of $\mathrm{WS}_{2}$ through a self-assembled double carbon coating. J Phys Chem C, 2015, 119: 15874-15881

$29 \mathrm{Hu} \mathrm{S}$, Chen W, Zhou J, et al. Preparation of carbon coated $\mathrm{MoS}_{2}$ flower-like nanostructure with self-assembled nanosheets as highperformance lithium-ion battery anodes. J Mater Chem A, 2014, 2: 7862-7872

30 Deng J, Chen L, Sun $\mathrm{Y}$, et al. Interconnected $\mathrm{MnO}_{2}$ nanoflakes assembled on graphene foam as a binder-free and long-cycle life lithium battery anode. Carbon, 2015, 92: 177-184

$31 \mathrm{Hu}$ X, Ma M, Mendes RG, et al. Li-storage performance of binderfree and flexible iron fluoride@graphene cathodes. J Mater Chem A, 2015, 3: 23930-23935

32 Lee SY, Choi KH, Choi WS, et al. Progress in flexible energy storage and conversion systems, with a focus on cable-type lithium-ion batteries. Energy Environ Sci, 2013, 6: 2414

33 Chen Y, Song B, Lu L, Xue J. Ultra-small $\mathrm{Fe}_{3} \mathrm{O}_{4}$ nanoparticle decorated graphene nanosheets with superior cyclic performance and rate capability. Nanoscale, 2013, 5: 6797-6803

34 Zhu C, Mu X, van Aken PA, et al. Fast Li storage in $\mathrm{MoS}_{2}$-graphenecarbon nanotube nanocomposites: advantageous functional integration of 0D, 1D, and 2D nanostructures. Adv Energy Mater, 2015, 5: 1401170

35 Mei L, Xu C, Yang T, et al. Superior electrochemical performance of ultrasmall $\mathrm{SnS}_{2}$ nanocrystals decorated on flexible RGO in lithiumion batteries. J Mater Chem A, 2013, 1: 8658-8664

36 Wang C, Li D, Too CO, Wallace GG. Electrochemical properties of graphene paper electrodes used in lithium batteries. Chem Mater, 2009, 21: 2604-2606

37 David L, Bhandavat R, Singh G. $\mathrm{MoS}_{2}$ /graphene composite paper for sodium-ion battery electrodes. ACS Nano, 2014, 8: 1759-1770

38 Slater MD, Kim D, Lee E, Johnson CS. Sodium-ion batteries. Adv Funct Mater, 2013, 23: 947-958

39 Xiong X, Luo W, Hu X, et al. Flexible membranes of $\mathrm{MoS}_{2} / \mathrm{C}$ nanofibers by electrospinning as binder-free anodes for high-performance sodium-ion batteries. Sci Rep, 2015, 5: 9254

40 Li Y, Zhu H, Shen F, et al. Nanocellulose as green dispersant for two-dimensional energy materials. Nano Energy, 2015, 13: 346-354

41 Xiao L, Cao Y, Xiao J, et al. High capacity, reversible alloying reactions in $\mathrm{SnSb} / \mathrm{C}$ nanocomposites for $\mathrm{Na}$-ion battery applications. Chem Commun, 2012, 48: 3321-3323

42 Sangster J. C-Li (carbon-lithium) System. J Phase Equilib Diffus, 2007, 28: 561-570

43 Zhang Y, Liu Z, Zhao H, Du Y. MoSe 2 nanosheets grown on carbon cloth with superior electrochemical performance as flexible electrode for sodium ion batteries. RSC Adv, 2016, 6: 1440-1444

44 Choi SH, Kang YC. Sodium ion storage properties of $\mathrm{WS}_{2}$-decorated three-dimensional reduced graphene oxide microspheres. Nanoscale, 2015, 7: 3965-3970

45 Share K, Lewis J, Oakes L, et al. Tungsten diselenide ( $\mathrm{WSe}_{2}$ ) as a high capacity, low overpotential conversion electrode for sodium ion batteries. RSC Adv, 2015, 5: 101262-101267

46 Liu B, Luo T, Mu G, et al. Rechargeable Mg-ion batteries based on $\mathrm{WSe}_{2}$ nanowire cathodes. ACS Nano, 2013, 7: 8051-8058

47 Luo W, Wan J, Ozdemir B, et al. Potassium ion batteries with graphitic Materials. Nano Lett, 2015, 15: 7671-7677

48 Freunberger SA, Chen Y, Peng Z, et al. Reactions in the recharge- 
able lithium $-\mathrm{O}_{2}$ battery with alkyl carbonate electrolytes. J Am Chem Soc, 2011, 133: 8040-8047

49 Zhang Q, Tan S, Kong X, et al. Synthesis of sulfur encapsulated 3D graphene sponge driven by micro-pump and its application in Li-S battery. J Materiomics, 2015, 1: 333-339

50 Salvatore GA, Munzenrieder N, Barraud C, et al. Fabrication and transfer of flexible few-layers $\mathrm{MoS}_{2}$ thin film transistors to any arbitrary substrate. ACS Nano, 2013, 7: 8809-8815

51 Zhang Y, Sun W, Rui X, et al. One-pot synthesis of tunable crystalline $\mathrm{Ni}_{3} \mathrm{~S}_{4} @$ amorphous $\mathrm{MoS}_{2}$ core/shell nanospheres for highperformance supercapacitors. Small, 2015, 11: 3694-3702

52 Bissett MA, Kinloch IA, Dryfe RA. Characterization of $\mathrm{MoS}_{2}$-graphene composites for high-performance coin cell supercapacitors. ACS Appl Mater Interfaces, 2015, 7: 17388-17398

53 Feng J, Sun $\mathrm{X}, \mathrm{Wu} \mathrm{C}$, et al. Metallic few-layered $\mathrm{VS}_{2}$ ultrathin nanosheets: high two-dimensional conductivity for in-plane supercapacitors. J Am Chem Soc, 2011, 133: 17832-17838

54 Javed MS, Dai S, Wang M, et al. High performance solid state flexible supercapacitor based on molybdenum sulfide hierarchical nanospheres. J Power Sources, 2015, 285: 63-69

55 Wu Z, Li B, Xue Y, et al. Fabrication of defect-rich $\mathrm{MoS}_{2}$ ultrathin nanosheets for application in lithium-ion batteries and supercapacitors. J Mater Chem A, 2015, 3: 19445-19454

56 Hao C, Wen F, Xiang J, et al. Controlled incorporation of $\mathrm{Ni}(\mathrm{OH})_{2}$ nanoplates into flowerlike $\mathrm{MoS}_{2}$ nanosheets for flexible all-solidstate supercapacitors. Adv Funct Mater, 2014, 24: 6700-6707

57 Ratha S, Rout CS. Supercapacitor electrodes based on layered tungsten disulfide-reduced graphene oxide hybrids synthesized by a facile hydrothermal method. ACS Appl Mater Interfaces, 2013, 5: $11427-11433$

58 Chakravarty D, Late DJ. Microwave and hydrothermal syntheses of $\mathrm{WSe}_{2}$ micro/nanorods and their application in supercapacitors. RSC Adv, 2015, 5: 21700-21709

59 Duan X, Wang C, Pan A, et al. Two-dimensional transition metal dichalcogenides as atomically thin semiconductors: opportunities and challenges. Chem Soc Rev, 2015, 44: 8859-8876

60 Lembke D, Bertolazzi S, Kis A. Single-layer $\mathrm{MoS}_{2}$ electronics. Acc Chem Res, 2015, 48: 100-110

61 Chhowalla M, Shin HS, Eda G, et al. The chemistry of two-dimensional layered transition metal dichalcogenide nanosheets. Nat Chem, 2013, 5: 263-275

62 Guo W, Zhang X, Yu R, et al. CoS NWs/Au hybridized networks as efficient counter electrodes for flexible sensitized solar cells. Adv Energy Mater, 2015, 5: 1500141

63 Pan $\mathrm{C}$, Niu S, Ding Y, et al. Enhanced $\mathrm{Cu}_{2} \mathrm{~S} / \mathrm{CdS}$ coaxial nanowire solar cells by piezo-phototronic effect. Nano Lett, 2012, 12: 3302-3307

64 Tahersima MH, Sorger VJ. Enhanced photon absorption in spiral nanostructured solar cells using layered 2D materials. Nanotechnology, 2015, 26: 344005

65 Chen J, Xu F, Wu J, et al. Flexible photovoltaic cells based on a graphene-CdSe quantum dot nanocomposite. Nanoscale, 2012, 4: 441-443

66 Que M, Guo W, Zhang X, et al. Flexible quantum dot-sensitized solar cells employing $\mathrm{CoS}$ nanorod arrays/graphite paper as effective counter electrodes. J Mater Chem A, 2014, 2: 13661-13666

67 Gao Z, Jin W, Li Y, et al. Flexible solar cells based on CdSe nanobelt/graphene Schottky junctions. J Mater Chem C, 2015, 3: 4511-4514

68 Tsai ML, Su SH, Chang JK, et al. Monolayer $\mathrm{MoS}_{2}$ heterojunction solar cells. ACS Nano, 2014, 8: 8317-8322

69 Shao Z, Jie J, Sun Z, et al. $\mathrm{MoO}_{3}$ nanodots decorated CdS nanorib- bons for high-performance, homojunction photovoltaic devices on flexible substrates. Nano Lett, 2015, 15: 3590-3596

70 Fan Z, Razavi H, Do JW, et al. Three-dimensional nanopillar-array photovoltaics on low-cost and flexible substrates. Nat Mater, 2009, 8: $648-653$

71 Lei S, Wen F, Ge L, et al. An atomically layered InSe avalanche photodetector. Nano Lett, 2015, 15: 3048-3055

72 Chen G, Wang W, Wang C, et al. Controlled synthesis of ultrathin $\mathrm{Sb}_{2} \mathrm{Se}_{3}$ nanowires and application for flexible photodetectors. Adv Sci, 2015, 2: 1500109

73 Chen G, Yu Y, Zheng K, et al. Fabrication of ultrathin $\mathrm{Bi}_{2} \mathrm{~S}_{3}$ nanosheets for high-performance, flexible, visible-NIR photodetectors. Small, 2015, 11: 2848-2855

74 Tao Y, Wu X, Wang W, Wang J. Flexible photodetector from ultraviolet to near infrared based on a $\mathrm{SnS}_{2}$ nanosheet microsphere film. J Mater Chem C, 2015, 3: 1347-1353

75 Tian W, Zhang C, Zhai T, et al. Flexible ultraviolet photodetectors with broad photoresponse based on branched $\mathrm{ZnS}-\mathrm{ZnO}$ heterostructure nanofilms. Adv Mater, 2014, 26: 3088-3093

76 Tao YR, Chen JQ, Wu JJ, et al. Flexible ultraviolet-visible photodetector based on $\mathrm{HfS}_{3}$ nanobelt film. J Alloys Compd, 2016, 658: 6-11

77 Tao YR, Wu XC, Xiong WW. Flexible visible-light photodetectors with broad photoresponse based on $\mathrm{ZrS}_{3}$ nanobelt films. Small, 2014, 10: 4905-4911

78 Tamalampudi SR, Lu YY, Kumar UR, et al. High performance and bendable few-layered InSe photodetectors with broad spectral response. Nano Lett, 2014, 14: 2800-2806

79 Hu P, Wang L, Yoon M, et al. Highly responsive ultrathin GaS nanosheet photodetectors on rigid and flexible substrates. Nano Lett, 2013, 13: 1649-1654

80 Wang Z, Safdar M, Mirza M, et al. High-performance flexible photodetectors based on GaTe nanosheets. Nanoscale, 2015, 7: 7252-7258

81 Zheng W, Xie T, Zhou Y, et al. Patterning two-dimensional chalcogenide crystals of $\mathrm{Bi}_{2} \mathrm{Se}_{3}$ and $\mathrm{In}_{2} \mathrm{Se}_{3}$ and efficient photodetectors. Nat Commun, 2015, 6: 6972

82 Gao Z, Jin W, Zhou Y, et al. Self-powered flexible and transparent photovoltaic detectors based on CdSe nanobelt/graphene Schottky junctions. Nanoscale, 2013, 5: 5576-5581

83 Chao J, Xing S, Zhang J, et al. Synthesis of $\mathrm{Sb}_{2} \mathrm{~S}_{3}$ nanowall arrays for high performance visible light photodetectors. Mater Res Bull, 2014, 57: 300-305

84 Wang Q, Xu K, Wang Z, et al. Van der Waals epitaxial ultrathin twodimensional nonlayered semiconductor for highly efficient flexible optoelectronic devices. Nano Lett, 2015, 15: 1183-1189

85 Zhang Y, Ji Q, Han GF, et al. Dendritic, transferable, strictly monolayer $\mathrm{MoS}_{2}$ flakes synthesized on $\mathrm{SrTiO}_{3}$ single crystals for efficient electrocatalytic applications. ACS Nano, 2014, 8: 8617-8624

86 Yang $\mathrm{Y}$, Fei $\mathrm{H}$, Ruan G, et al. Edge-oriented $\mathrm{MoS}_{2}$ nanoporous films as flexible electrodes for hydrogen evolution reactions and supercapacitor devices. Adv Mater, 2014, 26: 8163-8168

87 Peng S, Li L, Han X, et al. Cobalt sulfide nanosheet/graphene/carbon nanotube nanocomposites as flexible electrodes for hydrogen evolution. Angew Chem Int Ed, 2014, 53: 12594-12599

88 Benck JD, Lee SC, Fong KD, et al. Designing active and stable silicon photocathodes for solar hydrogen production using molybdenum sulfide nanomaterials. Adv Energy Mater, 2014, 4: 1400739

89 Jia L, Sun X, Jiang Y, et al. A novel $\mathrm{MoSe}_{2}$-reduced graphene oxide/polyimide composite film for applications in electrocatalysis and photoelectrocatalysis hydrogen evolution. Adv Funct Mater, 2015, 25: $1814-1820$ 
90 Morales-Guio CG, Thorwarth K, Niesen B, et al. Solar hydrogen production by amorphous silicon photocathodes coated with a magnetron sputter deposited $\mathrm{Mo}_{2} \mathrm{C}$ catalyst. J Am Chem Soc, 2015, 137: 7035-7038

91 Wu W, Wang L, Li Y, et al. Piezoelectricity of single-atomic-layer $\mathrm{MoS}_{2}$ for energy conversion and piezotronics. Nature, 2014, 514: $470-474$

Acknowledgments This work was supported by the National Natural
Science Foundation of China (51322209 and 21473124) and Sino-German Center for Research Promotion (GZ 871).

Author contributions Liu J, Cao H and Jiang B wrote the manuscript; $\mathrm{Fu} \mathrm{L}$ and Xue Y developed the concept and revised the manuscript; Liu J and Jiang B prepared the figures; Liu J and Cao H classified and analyzed the reference papers. All authors participated in the general discussion.

Conflict of interest The authors declare that they have no conflict of interest.

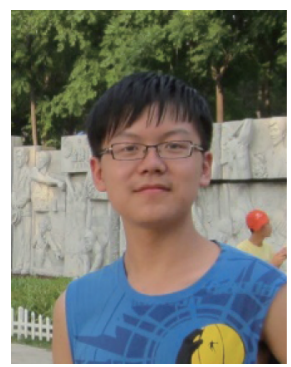

Jinxin Liu received his BSc degree from Wuhan University in 2015, and continued his studies as a PhD candidate under the supervision of Prof. Lei Fu in the College of Chemistry and Molecular Science at Wuhan University. His current research is focused on the controllable growth of two-dimensional materials.
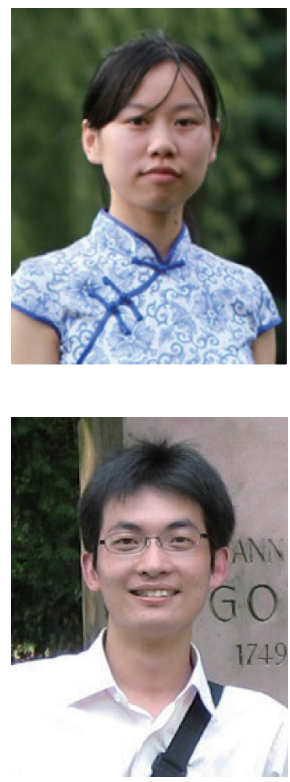

Hui Cao received her BSc degree in polymer materials and engineering from Wuhan Institute of Technology in 2015, and continued her studies under the supervision of Prof. Lei Fu in the College of Chemistry and Molecular Science at Wuhan University. Her current research is mainly focused on the application of two-dimensional materials in lithium ion batteries.

Lei Fu received his BSc degree in chemistry from Wuhan University in 2001. He obtained his PhD degree from the Institute of Chemistry, Chinese Academy of Sciences in 2006. Then he worked as a Director's Postdoctoral Fellow at Los Alamos National Laboratory, Los Alamos, NM (2006-2007). Thereafter, he became an Associate Professor of Peking University. In 2012, he joined Wuhan University as a Full Professor. His research interests include two-dimensional materials and energy devices.

\footnotetext{
新兴二维材料在柔性能源存储和转换中的应用

刘津欣, 曹慧, 江贝, 薛迎辉, 付磊

摘要 近年来, 智能可穿戴电子产品开始走入我们的日常生活, 同时也极大地激发了研究者们对柔性能源的研究兴趣. 以过渡金属二硫族 化合物为代表的新兴二维材料表现出了优秀的光电和机械性能、高的理论比容量等性质, 使其在柔性能源存储和转换领域备受关注. 相 比于零带隙且比容量低的石墨烯或者硅等传统材料, 这些新兴的二维材料在构筑柔性光电器件及二次电池方面具有良好的应用前景. 本 文综述了新型二维材料在二次电池、超级电容器、太阳能电池、光电探测器和纳米发电机等柔性能源应用领域的突破性进展. 虽然目前 这个新兴领域仍面临众多问题, 但是通过结构与材料的设计与优化, 有望在不久的将来逐步得到解决. 我们相信这些新兴二维材料的应用 将显著提高柔性能源器件的性能, 并推动可穿戴电子产品在我们日常生活中的普及.
} 